\title{
NOMBRAR LO INNOMBRABLE, O LO DIFÍCIL QUE RESULTA CRITICAR EL PODER PROFESIONAL - DESDE LA PROFESIÓN (A PROPÓSITO DE IVAN ILLICH) ${ }^{1}$
}

\section{Mariano Fernández Enguita}

\section{RESUMEN}

La reciente muerte de Ivan Illich ha traído a la memoria un nombre, un hombre y unas ideas que, hace un cuarto de siglo, tuvieron una importante repercusión en el mundo de la enseñanza, para luego pasar rápidamente al olvido sin pena ni gloria. La pregunta es: ¿por qué? ¿Por qué nadie se acuerda de Illich, aunque todos se acuerdan de Freire, Bourdieu, Bernstein o Milani, por citar sólo otros nombres vinculados al cuestionamiento radical de la institución escolar en los inicios de la década de los setenta? O, mejor dicho: ¿por qué apenas se recuerda de Illich su provocadora, por no decir exótica, propuesta, desescolarizar la sociedad, pero no así los argumentos en que se sustentaba?

\section{PALABRAS CLAVES}

Historia de educación; Ivan Illich.

\section{INNOMBRABLE NAME, O HOW HARD IT IS CRITICAL POWER TRAINING - FROM THE PROFESSION (A PURPOSE OF IVAN ILLICH)}

\begin{abstract}
Ivan's recent death Illich has brought to the memory a name, a man and some ideas that, a century room ago, they had an important repercussion in the world of the teaching, it stops then to pass quickly to the forgetfulness without pain neither glory. The question is: why? Why does nobody remember Illich, although all remember of I will Fry, Bourdieu, Bernstein or Milani, to only mention other names linked to the radical question of the school institution in the beginnings of the decade of the seventy? Or, rather: why do you grieve he/she remembers of Illich their provocative one, for not saying exotic, proposal, desescolarizar the society, but didn't I seize the arguments in that it was sustained?
\end{abstract}

\section{KEYWORDS}

History of education; Ivan Illich

\footnotetext{
${ }^{1}$ Iván Illich murió el dos de diciembre de 2002 en la Universidad de Bremen en Alemania, mientras dormía. Nos abandona la persona física, no el ejemplo indeleble de su obra. Era un hombre intensamente bueno con sus semejantes (en particular con la gente pobre y sencilla), pero despiadadamente crítico de las instituciones y creencias que socaban la libertad y la convivencia pacífica de los hombres que luchan cotidianamente por su libertad y cultura. Era un rebelde, como lo son los niños en el juego creador de hacer el mundo más habitable, pero también era un sabio que supo ver en el espejo del pasado la decadencia del presente y visualizar alternativas para un futuro en tránsito a la convivencia pacífica por los caminos de la libertad.
} 
La reciente muerte de Ivan Illich ha traído a la memoria un nombre, un hombre y unas ideas que, hace un cuarto de siglo, tuvieron una importante repercusión en el mundo de la enseñanza, para luego pasar rápidamente al olvido sin pena ni gloria. La pregunta es: ¿por qué? ¿Por qué nadie se acuerda de Illich, aunque todos se acuerdan de Freire, Bourdieu, Bernstein o Milani, por citar sólo otros nombres vinculados al cuestionamiento radical de la institución escolar en los inicios de la década de los setenta? O, mejor dicho: ¿por qué apenas se recuerda de Illich su provocadora, por no decir exótica, propuesta, desescolarizar la sociedad, pero no así los argumentos en que se sustentaba? Sencillamente, porque tocó en hueso, porque no intentó atribuir los males de la educación a fuerzas lejanas, como el capital o los gobiernos, sino esencialmente a la institución misma y a la profesión docente (así como los de la salud a la medicina y a los médicos, etc.), y en vez de regodearse en esta lamentación autocomplaciente que consiste en culpar a la sociedad de los males de la escuela señaló en esta institución una de las causas del malestar social, si es que no la causa principal, en el caso de las sociedades industrializadas. La obra de Illich era, en verdad, un cúmulo de errores, pero no fueron éstos, sino un incómodo acierto en medio de ellos, lo que lo condenó a desaparecer en el limbo de los justos.

\section{EN LAS POSTRIMERÍAS DE MAYO}

Illich publicó su obra en un momento propicio: todavía estaban frescas las movilizaciones estudiantiles (no sólo universitarias, sino también muy amplias en la enseñanza secundaria) en torno a 1968, sobre todo en los países europeos (incluidos los sometidos a dictaduras en el Oeste e incluso en el Este) y norteamericanos (incluido México, donde entonces vivía y trabajaba él). En ese momento, una crítica radical a la escuela no podía sino ser bien recibida, pues la institución sufría un cuestionamiento que iba más allá de su eventual instrumentalización por el capitalismo o por el socialismo burocrático. Llama la atención la distinta acogida de dos obras equiparables de Illich: Deschooling Society y Medical Nemesis. La primera, Desescolarizar la sociedad (un título programático mal traducido aquí por La sociedad desescolarizada, que bien podría haber elegido cualquier partidario de aumentar la escolarización), era una obra estimulante, provocadora en el mejor sentido, que planteaba una crítica refrescante a lo que parecía evidente para derecha e izquierda, la bondad indiscutible de la escolarización, pero era también un obra relativamente 
floja. Creo que resultó ser bastante más sólida la de su colaborador y seguidor, Emrett Reimer, La escuela ha muerto.

Para mi gusto, Némesis médica es una obra más incisiva, más acertada (aunque sus clasificaciones de los tratamientos o los fármacos en buenos y malos harían hoy sonreír, pues no en vano ha pasado un cuarto de siglo), y dirigida contra la profesión entre las profesiones, la más alejada del escrutinio público. Sin embargo, su impacto fue mucho menor, como lo indica el simple hecho de que de la primera se hiciesen en España cuatro ediciones en los setenta y de la segunda sólo una hasta hoy. La explicación hay que buscarla en las diferencias entre las dos profesiones: medicina y educación. Primero, en la mayor fuerza política y legitimidad social de la medicina; segundo, en la notablemente mayor receptividad hacia las críticas de la docente; tercero, pero no menos importante, en que la medicina es una profesión liberal en la que el contacto médico-paciente es ocasional aunque reiterado, mientras que la docencia es una profesión organizacional en la que la relación profesoralumno es sistemática y continuada. De hecho, por esas fechas se libraba una batalla, la de la antipsiquiatría y la desinstitucionalización, a resultas de la cual la profesión médica se vería liberada de su faceta más propiamente burocrática: los internados.

La novedad del planteamiento de Illich no estaba en la crítica de la fenomenología de la escuela. De hecho, ésta ya había sido expuesta de forma más incisiva en obras como las de Henry (Essays on education), Silberman (Crisis in the classroom), Cicourel y Kitsuse (The educational decision-makers), Jackson (Life in classrooms) o Kozol (Death at an early age), por ejemplo.

Considerada la escuela como un proceso de producción, es decir, como un proceso que tiene por efecto la modificación de su objeto, los alumnos (modificación de sus conocimientos, sus actitudes, sus autoestima, sus expectativas...), la descripción de Illich era más bien superficial en comparación con las mencionadas (pero, paradójicamente $-\mathrm{o}$ no, como ya veremos-, éste fue el aspecto mejor aceptado de su crítica, pues venía a redundar en lo que pronto iba a convertirse en un tópico: la relevancia del currículum oculto). La novedad de sus planteamientos residía más bien en otros dos aspectos: su crítica de la escuela como mecanismo de distribución (del conocimiento, de las probabilidades de acceso al empleo, de las oportunidades vitales) y su crítica del papel de la profesión docente (y, en general, de las profesiones del Estado del bienestar). 


\section{UNA SALUDABLE INCORRECCIÓN POLÍTICA}

En su aspecto productivo, la crítica de Illich a la escuela se centraba en la pérdida de autonomía de los individuos, lo mismo que su crítica a la medicina o a los medios de transporte. Su defensa de los libros, los antibióticos (autoadministrados) o las bicicletas frente a las escuelas, los hospitales o el automóvil rezumaba una preferencia mal disimulada por lo pequeño (...es hermoso), una nostalgia inconfesa por la sencillez de la comunidad frente a las complejidades de la sociedad (como en tantos críticos de la sociedad, por cierto: Maine, Tönnies, Durkheim, incluso Marx y Weber). El problema sería que, confiando su salud o su educación a otros, a profesiones e instituciones, los individuos olvidan cómo aprender o mantenerse sanos por sí mismos y se vuelven, por ello mismo dependientes. Resuena aquí ese “quiero/no quiero" ante la división del trabajo y sus efectos que Marx había satirizado ya en Proudhon, la pretensión de hacerse con los resultados del progreso (los avances tecnológicos) sin aceptar sus medios (la especialización del trabajo).

En lo que hace a su función distributiva, en cambio, la crítica de Illich se centraba en un aspecto bastante más sencillo y evidente, que la retórica igualitaria no podía ocultar pero que era obstinadamente ignorado por tirios y troyanos, es decir, por sus defensores y sus detractores, por la izquierda y la derecha: el hecho de que la escolarización siempre sería insatisfactoria y desigual. Por un lado, porque la riqueza de la escolarización de unos definía en contrapartida la pobreza de la de los otros, y esa pobreza relativa nunca habría de desaparecer. Por otro, porque la escolarización misma era para él la iniciación al mito del consumo sin fin: de la mensurabilidad de los valores, de los valores envasados, del progreso que se perpetúa a sí mismo. En un lenguaje enrevesado, Illich venía a exponer el carácter antiigualitario de las promesas meritocráticas de la escuela, pero al mismo tiempo presentaba desnudo el flanco en el que mordería con mayor convencimiento la crítica marxista: su aparente pretensión de explicar la producción por el consumo, la sociedad por la escuela, etc.

De esta crítica de la función distributiva de la escuela derivarían algunas de sus observaciones más provocativas, a veces de una ostentosa incorrección política. Por ejemplo, la propuesta de recortar los presupuestos dedicados a la educación o la sanidad, ya que en su visión no mejoraban ni la sabiduría ni la salud de la población. 
Illich se complacía en contradecir los tópicos sobre la financiación de los servicios públicos, comparando la moderna economía de la salud con la medieval teología de las indulgencias o afirmando que se gasta más en medicina por un pobre que por un rico (algo que la evidencia no parece mostrar, a no ser que uno se limite a la medicina pública, en cuyo caso es una perogrullada). Pero su crítica de la educación era, en este punto, menos ligera, al señalar que su financiación pública es un sistema de tributación regresiva por el que se da más a los que menos lo necesitan, dado que son quienes permanecen más tiempo en ella. De ahí su defensa de los cheques escolares, sobre los que añadía que deberían ser simplemente educativos (para ser gastados en educación, pero no necesariamente en la escuela), bestia negra de los incondicionales de la escuela estatal que, sin embargo, todavía no ha sido objeto de una crítica (ni de una defensa) convincente. En fin, qué decir de su propuesta de una nueva enmienda a la Constitución norteamericana que añadiese a las prohibiciones de discriminar a las personas por razón de su raza, lengua o religión la de hacerlo por sus diplomas escolares, cuando el pensamiento conservador pretendía legitimar las desigualdades de propiedad como basadas en diferencias de conocimiento (capital humano, nuevas clases medias, directivos en vez de propietarios, etc.) y la izquierda parecía cifrar su idea de la igualdad en un mundo en que no hubiera otras diferencias que las marcadas por la educación (por el "valor” del trabajo).

\section{LA AUTONOMÍA DE LA PROBLEMÁTICA EDUCATIVA}

Pero el punto más interesante de su crítica, el niño que nunca debió perderse por el desagüe con el agua sucia, era su crítica de las profesiones vinculadas a los servicios públicos (las burocracias, en sus términos). Illich fustigaba sin piedad la pretensión de medicalizar o escolarizar más y más etapas y facetas de la vida, la insaciabilidad de las profesiones, a la vez que la pretensión de que su costosa formación fuese garantía suficiente de su buen trabajo, escapando así a cualquier escrutinio público o control por el cliente. Piénsese que la expansión de los servicios públicos del Estado del Bienestar (educación, sanidad, servicios sociales) era precisamente el punto de encuentro entre la izquierda y la derecha... para beneficio, al menos, de los profesionales. La izquierda veía a su enemigo en el mercado, en la propiedad privada, y la salvación en el Estado, en la autoridad pública, y la derecha exactamente lo inverso, y ninguna de las dos encontraba problema alguno en la expansión de las profesiones y de las instituciones a ellas vinculadas. Ése fue el gran acierto de Illich: 
captar el hecho de que las profesiones y sus clientelas dependientes (a la vez que la estratificación social del trabajo de acuerdo con la cualificación) forman parte de otra relación de poder, que son otro pilar de la desigualdad, sólo que basado en la distribución asimétrica del conocimiento en vez de los medios de producción o el mando sobre las personas.

Un buen ejemplo tanto de la incomodidad como de las limitaciones de la crítica de la izquierda contra Illich se encuentra en un, por lo demás, interesante librito publicado en España en 1976: Crítica de Ivan Illich, que reunía dos ensayos independientes de dos neomarxistas de entonces, dos brillantes analistas de la educación y de la medicina respectivamente, H. Gintis (“Crítica del illichismo”) y V. Navarro (“La industrialización del fetichismo o el fetichismo de la industrialización”). La crítica de ambos puede resumirse en que Illich trata de explicar la producción desde el consumo (o la sociedad desde la escuela) y no al revés, con lo cual deja de lado el elemento determinante: el capitalismo; dicho en breve, que se aparta de la ortodoxia marxista, lo cual puede ser terrible y definitivo desde el punto de vista de ésta, pero indiferente desde cualquier otro. El artículo de Gintis permite comprender mejor la incapacidad del marxismo y, más en general, de la izquierda de los setenta para adoptar una actitud crítica ante las profesiones y, en última instancia, ante la división del trabajo como un proceso autónomo aunque entrelazado con la acumulación del capital: "Las relaciones sociales en un sistema de educación no alienado [quería decir post-capitalista, de transición al socialismo, MFE] deben proceder de la cooperación y de las luchas conscientes entre la administración (los managers), los profesores (los técnicos) y los estudiantes (los trabajadores), si bien en un contexto donde el poder habrá sido redistribuido de manera radicalmente nueva entre las tres fuerzas”. Este paralelismo entre administración educativa / profesores / estudiantes, por un lado, y directivos / técnicos / trabajadores, por otro, se presta fácilmente a réplica, pero lo que importa aquí es solamente su función: exonerar a los profesores de toda responsabilidad (salvo quizá por omisión, por no oponerse a las autoridades) en los problemas de la educación.

Al equiparar los profesores a "los técnicos, interesados en la racionalidad científica de la producción”, quedaban transformados, como poco, en un colectivo neutral y, tal vez, en la fuerza progresiva por excelencia (¡la racionalidad científica!), situándose en todo caso por encima y más allá del conflicto entre los estudiantes-proletarios y las autoridades-capitalistas, au dessus de la melée (en la crítica de Navarro ni siquiera se mencionaba a la profesión médica). Una visión muy tranquilizante para el gremio: en general, se puede interpretar la 
crítica neomarxista de la escuela, con su empeño en presentar como omnipotente la mediata y lejana influencia del capital e ignorar la inmediata de la profesión (y, en correspondencia, en exagerar la imagen del Estado en cuanto instrumento del capital y difuminarla en cuanto escenario e instrumento de la profesión), como una empresa sistemática de restablecimiento de la legitimidad de ésta última contra la corriente deslegitimadora generada por la permanente crisis de la institución.

La mejor aportación de Illich fue precisamente sacar el debate sobre la escuela de la sórdida dialéctica-capital trabajo. No quiero decir con ello que las relaciones de producción estrictamente capitalistas no tengan influencia sobre la escuela o no deban ser tomadas en cuenta para su análisis, pues difícilmente podría dejarse de lado el pivote de la economía, y yo mismo he trabajado profusamente en esa línea. Pero pretender analizar la escuela sólo, fundamentalmente o en última instancia a partir de ellas es una simplificación grosera que sólo indica la pereza mental del analista y la fuerza política e ideológica de las racionalizaciones y autolegitimaciones del analizado.

El gran acierto de Illich fue señalar que se trata de un consumo especial y una producción especial. Como "consumo", estamos ante lo que la sociedad ha llegado a considerar un derecho al mismo que tiempo que una medida del valor individual, con lo cual se desata una dinámica a la vez igualitaria y meritocrática, lo que significa potencialmente explosiva. Como "producción” no se trata de un proceso más que involucra a un colectivo cualquiera, sino de una forma de procesamiento de las personas por un grupo profesional. Si combinamos una cosa y otra tenemos la insatisfacción permanente de los “consumidores” y el mejor de los mundos posibles para los productores.

\section{LOS LÍMITES DE LA CRÍTICA DE ILLICH}

Ahora bien, la absolutización y unilateralización de esta crítica es el principal límite de Illich. Que la institución sea alienante o la profesión insaciable no significa que su público pueda pasarse sin ellas. Proponer que cada cual se ocupe de su propia educación (o de su propia salud, o que se mueva en bicicleta) es sencillamente tan disparatado como pretender que hornee su propio pan, hile, teja y confeccione su propia ropa, construya su propia casa o cultive sus propios alimentos; sólo los más pobres se ven obligados a hacerlo, con magros resultados. Las instituciones y las profesiones que se ocupan de las personas son parte de la 
división del trabajo por la cual pasamos de una economía de subsistencia a otra de intercambio y cooperación, de consumir lo que producimos y producir lo que consumimos a consumir bienes y servicios que han producido otros y producir bienes o servicios que consumirán otros. Donde quiera que esa producción resulta ser un proceso complejo y su producto algo de difícil evaluación, aparece una profesión en el sentido fuerte del término; y, donde quiera que el producto es alguna modificación de las personas mismas, es decir, de su conducta, aparece una institución, o sea, una organización en la que un grupo profesional (la plantilla) procesa a un grupo profano (los institucionalizados), con distintos grados de intensidad según la naturaleza del “material” y de la "producción” (guardianes y presos, médicos y enfermos, profesores y alumnos, administradores y administrados...).

No existe otra alternativa global a estas instituciones que la desinstitucionalización, es decir, la destrucción de la sociedad, la vuelta a las pequeñas comunidades autosuficientes. Pero las pequeñas comunidades nunca han sido, en realidad, autosuficientes, salvo cuando han podido perderse en la selva. Cuando no, han estado sometidas a formas más o menos desnudas de poder, tales como los ejércitos imperiales, y en sí mismas han sido cualquier cosa menos escenarios de libertad para los individuos. Esto es lo que afirmaban nuestros antepasados medievales cuando decían: Stadtluft macht frei (el aire de la ciudad hace libre). La familia, la aldea, en la medida en que monopolicen la vida del individuo, son siempre agobiantes, y sólo pueden ser añoradas desde una visión ideológica y falsa del pasado. Las instituciones, como las organizaciones en general (las burocracias de Illich) pueden ser poderosas, incluso aplastantes, pero no son únicas, son múltiples, son susceptibles de elección... Un mundo de organizaciones en el que cada cual reparte su existencia entre varios tipos de ellas (trabajo, ocio, estudio, vida religiosa, participación política...) e incluso puede elegir dentro de cada tipo (empresa, partido, iglesia, incluso escuela...) es indiscutiblemente más libre que el pequeño mundo de las formas sociales primarias o naturales, en el que todo discurre dentro de una familia, una aldea, una tribu... Las instituciones, por supuesto, pueden ser más o menos alienantes, más o menos participativas, más o menos absorbentes, únicas o múltiples, monopolistas o competitivas, y de ello dependerá en buena parte la calidad de nuestra vida en ellas. Pero lo que no es pensable es un mundo en el que podamos disfrutar de los productos de las economías de escala sin alcanzar la escala, de independencia respecto de las formas sociales primarias sin haber desarrollado con fuerza las secundarias, etc. 
En otras palabras, un mundo sin escuelas no es hoy más que una entelequia. Illich nos ayudó a abrir los ojos ante la dinámica opresiva inherente a la institución escolar y los intereses corporativos de la profesión, pero sin proponer otra respuesta que el retorno imposible a un pasado inexistente. No era una utopía, sino una ucronía. La tarea de quienes creen posible otra educación no estriba en imaginar un implausible mundo desinstitucionalizado, sino en democratizar de arriba abajo unas instituciones de las que no sabríamos prescindir.

\section{REFERÊNCIAS}

ILLICH, I. Sociedade sem escolas. Petrópolis : Vozes, 1982.

Energía y equidad. México : Joaquín Mortiz, 1985.

Alternativas, Introducción por Erich Fromm. México : Joaquín Mortiz, 1977. 189p.

Alternativas II. México : Joaquín Mortiz ; Planeta, 1988. 190p. 